\title{
Depression and Ischemic Heart Disease or Ischemic Heart Disease and Depression?
}

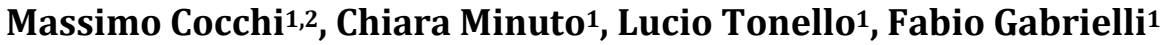 \\ 1"Paolo Sotgiu” Institute for Research in Quantitative \& Quantum Psychiatry \& Cardiology, \\ Lugano-Pazzallo, Switzerland \\ ${ }^{2}$ Department of Veterinary Medical Sciences, University of Bologna, Ozzano Emilia, Italy \\ Email: massimo.cocchi@unibo.it
}

How to cite this paper: Cocchi, M., Minuto, C., Tonello, L., \& Gabrielli, F. (2016). Depression and Ischemic Heart Disease or Ischemic Heart Disease and Depression? Open Journal of Depression, 5, 29-39. http://dx.doi.org/10.4236/ojd.2016.54004

Received: July 23, 2016

Accepted: September 27, 2016

Published: September 30, 2016

Copyright (C 2016 by authors and Scientific Research Publishing Inc. This work is licensed under the Creative Commons Attribution International License (CC BY 4.0).

http://creativecommons.org/licenses/by/4.0/ (c) (i) Open Access

\begin{abstract}
This editorial highlights how difficult is the correlation between Mood Disorder and Ischemic Heart Disease. In particular, it highlights the serious problem of suicide risk. This long-standing problem, object of controversy in the scientific literature, requires insights that should avoid simple surveys entrusted to the questionnaires, and the subjectivity of the clinical judgment. The text of the Editorial suggests the opportunity for substantial insights in the study of biological markers that give greater certainty of psychiatric diagnosis. The effort of the authors, in this sense, has proved highly effective in recognizing some of the major psychiatric disorders (Major Depression, Bipolar Disorder, Obsessive Compulsive Disorder and suicidal thoughts). Much work, however, remains to be done. The further suggestion which can be obtained from the script is that the complexity of mental phenomena must be faced with complex mathematical tools, to find diagnostic certainty and not diagnosis of opinion.
\end{abstract}

\section{Keywords}

Mood Disorder, Cardiovascular Disease, Suicide Risk, Cholesterol, Linoleic Acid

\section{Introduction}

Many authors have dealt with the attempt to understand the relationship between depressive disorder and cardiovascular disease, as well as the role of cholesterol as a risk factor in the respective diseases.

Recently, Cocchi et al. (2016) in a letter to the Editor of the BMJ Open, demonstrate the lack of importance of cholesterol in cardiovascular risk and that the assessment made by an Artificial Neural Network (Self-Organizing Map/SOM) and by a biochemical 
index (Stearic/Oleic ratio) for the classification of patients with a coronary plaque, was perfectly overlapping the physiological risk for age of the Framingham study, corresponding, at least, to 5000 cases. This shows the strong power of the Artificial Neural Network when the biological relationships are complex (Cocchi \& Tonello, 2010).

In this direction, it becomes important to clarify the relationship between serotonin and cholesterol, and also, in the light of experimental data, try to give a possible and plausible contribute to this intriguing problem.

\section{Cholesterol and Serotonin}

Acute coronary syndrome is characterized by a substantial decrease in total cholesterol (Balci, 2011), as well as an aberrant lipid metabolism has been reported in coronary patients with and without depression (de Jonge et al., 2010; Stapelberg et al., 2011).

Other data show significant lipid abnormalities in patients with mood disorders (Cocchi \& Tonello, 2010; Benedetti et al., 2014; Fava et al., 1996).

There are also many evidences linking a low level of cholesterol to depression and suicide risk (Partonen et al., 1999; De Berardis et al., 2012; Rabe-Jablonska \& Poprawska, 2000; Boston et al., 1996; Kaplan et al., 1997).

It was suggested, also, that cholesterol in synaptic membranes may determine the number of serotonin receptors (Engelberg, 1992) and that cholesterol abnormalities may be involved with alterations of serotonergic mechanisms. Cholesterol, in addition, participate, substantially to the functional homeostasis of the membranes to regulate, together with the phospholipid fraction, their mobility (Cocchi et al., 2011; Cocchi et al., 2010). More the cell membrane is viscous, more serotonin receptors are exposed, more is fluid, the serotonin receptors internalize and the uptake of serotonin does not occur (Tonello \& Cocchi, 2010).

Other studies have demonstrated the role of cholesterol in the organization and function of the 5-HT1A receptors (Payla et al., 2008), furthermore chronic cholesterol depletion reduces the coupling of $\mathrm{G}$ protein of the 5-HT1A receptors (Shrivastava et al., 2010).

Literature further investigates the total cholesterol levels in depressed patients to assess the risk of suicide (Kim et al., 2014).

In this long-standing dispute between those who find high or low cholesterol in mood disorders, an interesting paper (Payla et al., 2008) shows how it is fundamental the brain region in which cholesterol levels are reduced and this area is the medial prefrontal cortex, which is also the area of the decision-making ability. Cholesterol is not the main responsible for the ischemic heart disease and of the combined risk of depression and ischemic heart disease. In fact, we will see how novel markers identified by the SOM [some platelet fatty acids: Oleic, Linoleic and Arachidonic Acid for ischemic heart disease and Palmitic, Linoleic and Arachidonic Acid for depression] can explain, in a biochemical key, the interactions between depression and ischemia. 
Before addressing this part, we try to clarify, in the light of recent acquisitions, the interdependence of the two phenomena (Depression and Cardiovascular Disease).

\section{Depression and Cardiovascular Disease}

Depression is a prevalent manifestation in patients with heart disease [stable CAD (Coronary Artery Disease), unstable angina, myocardial infarction]. In CAD, it is detected an incidence of Major Depression (MD) of at least three times higher than the general population (Kessler et al., 2003) and similar to that seen in chronic renal disease (Hedayati et al., 2006).

Even those who undergo cardioinversion-defibrillation, patients with heart failure and atrial fibrillation are at serious risk of onset of the depressive phenomenon, mostly considered as Major Depression (Magyar-Russell et al., 2011; McCabe, 2010).

A meta-analysis of patients with Heart Failure found an incidence of about $40 \%$ of dysthymia, Bipolar Disorder (BD), or MD, which represents the $15 \%$ of the total (Tully \& Baker, 2012). However, these data are reported with diagnostic questionnaires, with subjective evaluations and not with biological objective data. In fact, it is known, that there is a diagnostic misinterpretation which ranges from $40 \%$ (Bowden, 2001) to $70 \%$ (Tenth World Day forth Prevention of Suicide, 2012).

Another recent paper (Hoffman et al., 2011) details a little better the relation depressionheart disease.

The prevalence of unrecognized depression in cardiac patients has been known for over 40 years.

In a survey conducted in 1967 (Wynn, 1967) in Australia, on heart patients, the perception of a depressive tendency has been estimated in $40 \%$ of the sample and, for many of the subjects, not previously recognized. In 1972 (Cay et al., 1972), symptoms of anxiety and depression were detected in $2 / 3$ of patients after cardiac event.

Because depression is a common occurrence in the CVD (Cardiovascular Disease), Hare et al. (2014) wonder if the CVD leads to depression or vice versa, and they point out that there are no arguments that depression is a marker for an increased incidence of CVD (Colquhoun et al., 2013; Nicholson et al., 2006).

Regarding the causality of the relationship between depression and CVD, about the incidence and prognosis, it should be demonstrated that depression is a risk factor rather than a marker.

Besides all the studies conducted (Nicholson et al., 2006; Barefoot \& Schroll, 1996) to show that depression is a risk factor, it would be necessary:

1. A longitudinal adjustment of patients that includes objective and perspective measurements of CVD.

2. That there is a strong, consistent and gradual relationship.

3. That the association cannot be explained by known covariates.

4. That there is the presence of potential and plausible biological mechanisms.

5. That there is evidence that altering the risk factors the prognosis changes.

An experimental design is practically impossible. 


\section{Ischemic Heart Disease and "Depression" or Depression and Ischemic Heart Disease}

The summary of the work by Cocchi et al. (2011) describes the steps of the research that led to the classification of patients with ischemia and depression, using platelet fatty acids and a SOM. All pathological subjects were accurately identified (Major Depression (MD), Bipolar Disorder (BD) and Coronary plaque).

Each case has been recognized by the SOM providing a comprehensive picture of gravity with respect to the $\mathrm{CAD}$ and the recognition of cases of $\mathrm{MD}$ and $\mathrm{BD}$. Within these two pathologies the SOM has further recognized cases of Obsessive Compulsive Disorder, severe psychosis and suicide attempt (Benedetti et al., 2014). Out of the descriptive phase of research and because of the conflictual hypothesis of the scientific literature on the controversial interdependence of depression and coronary heart disease (Hare et al., 2014), we have considered the subjects studied by evaluating crosswise the "depressed patients" within the SOM of ischemia and the ischemic patients within the SOM of depression. Below the results which are reported visually through the maps built by the SOM for Ischemic Heart Disease (CAIN) and Mood Disorders (ADAM) in the first experimental phase (Figures 1-4).

The following maps show how the Depressive subjects are distributed with respect to the cardiovascular risk and Ischaemic subjects with respect to the depressive risk (Figure 5, Figure 6).

After having recognized the MD subjects and the $\mathrm{BD}$ subjects, it was made the same assessment (Figures 7-9).

As can be seen the majority of people with mood disorders (Figure 7, Figure 8) is not classified in the area of patients with ischemia.

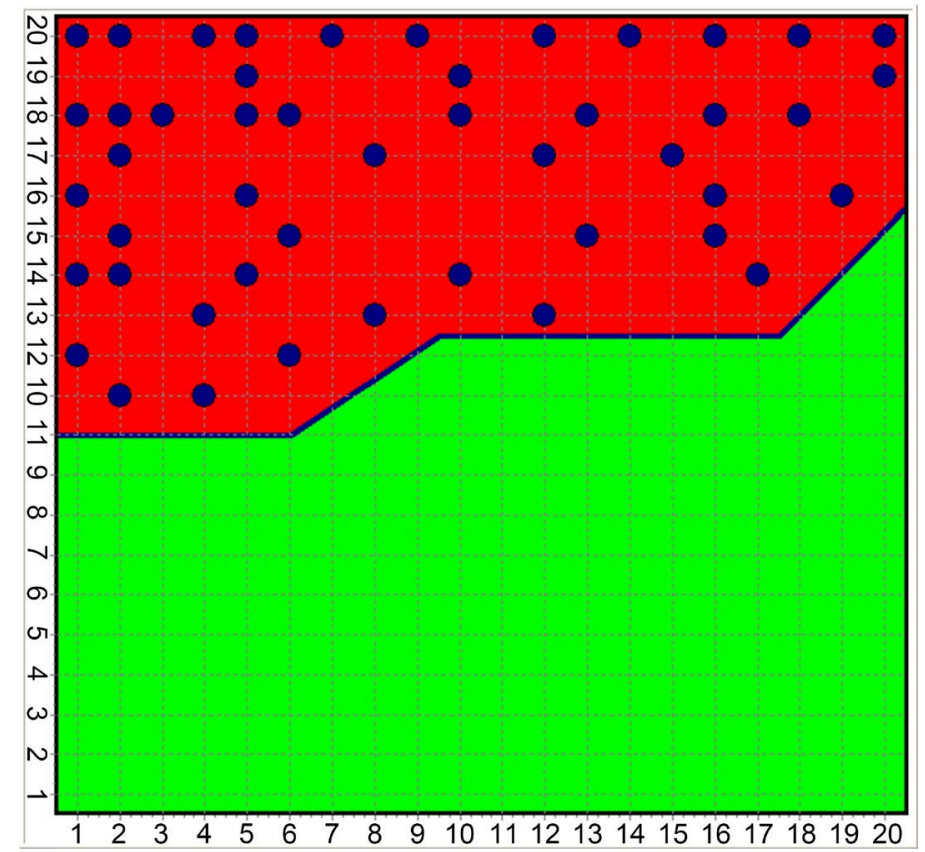

Figure 1. Classification of ischemic patients in CAIN (red area). 


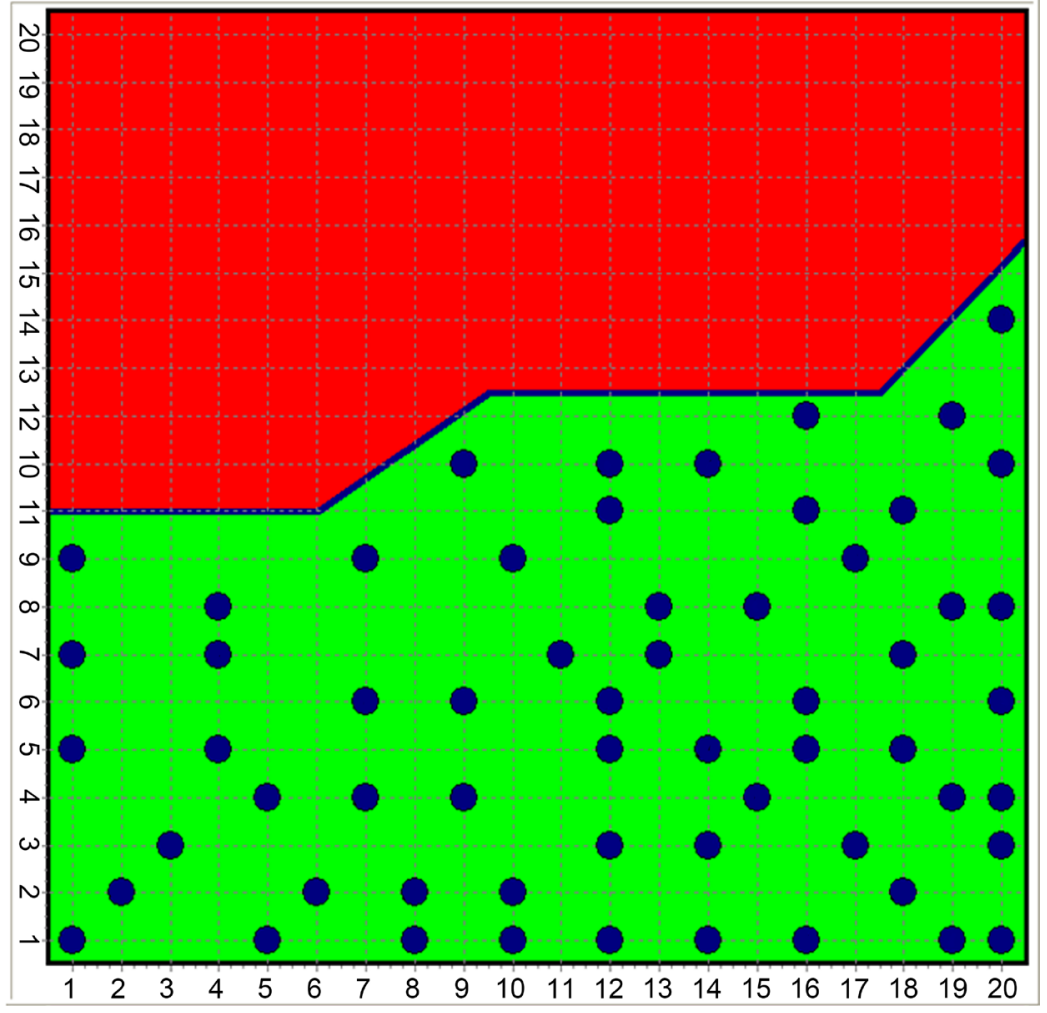

Figure 2. Classification of normal subjects in CAIN (green area).

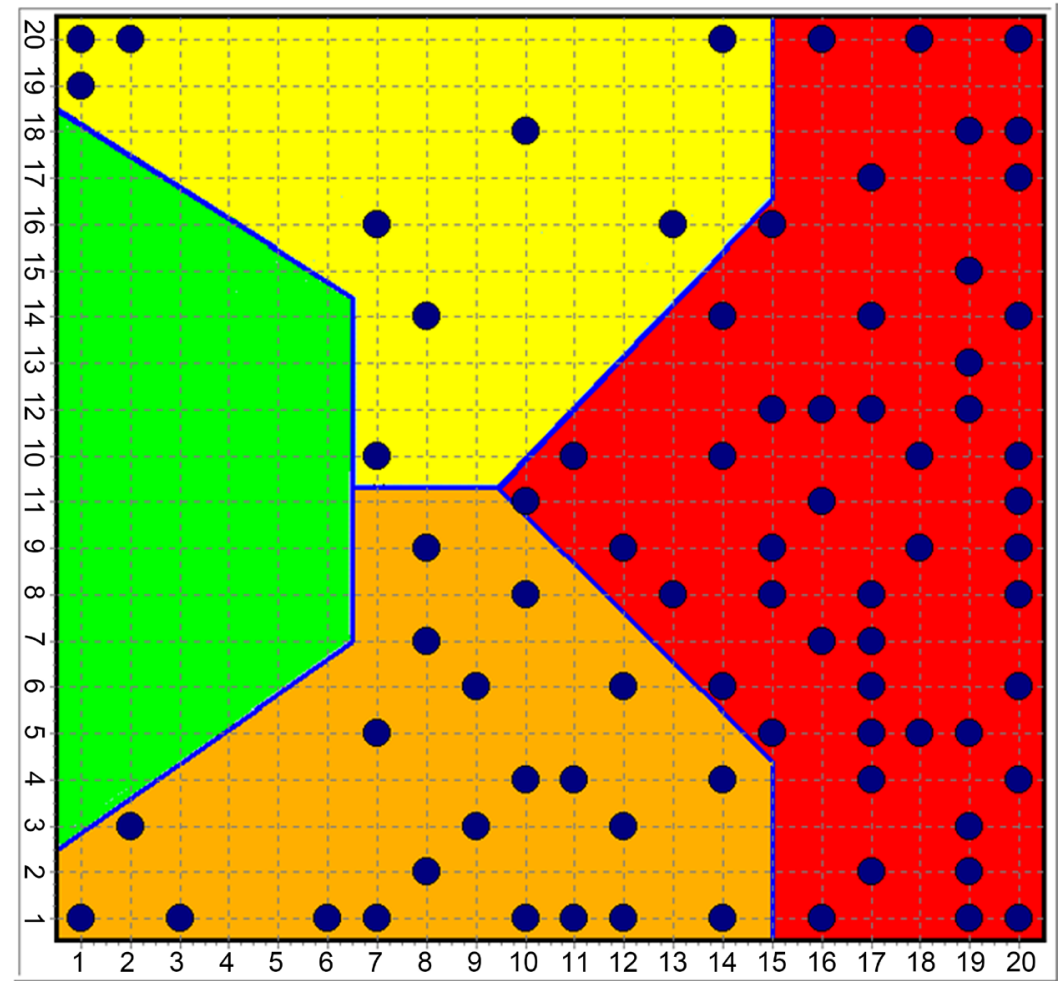

Figure 3. Distribution of patients with mood disorders in ADAM (green = normal; red, yellow and orange $=$ pathologic). 


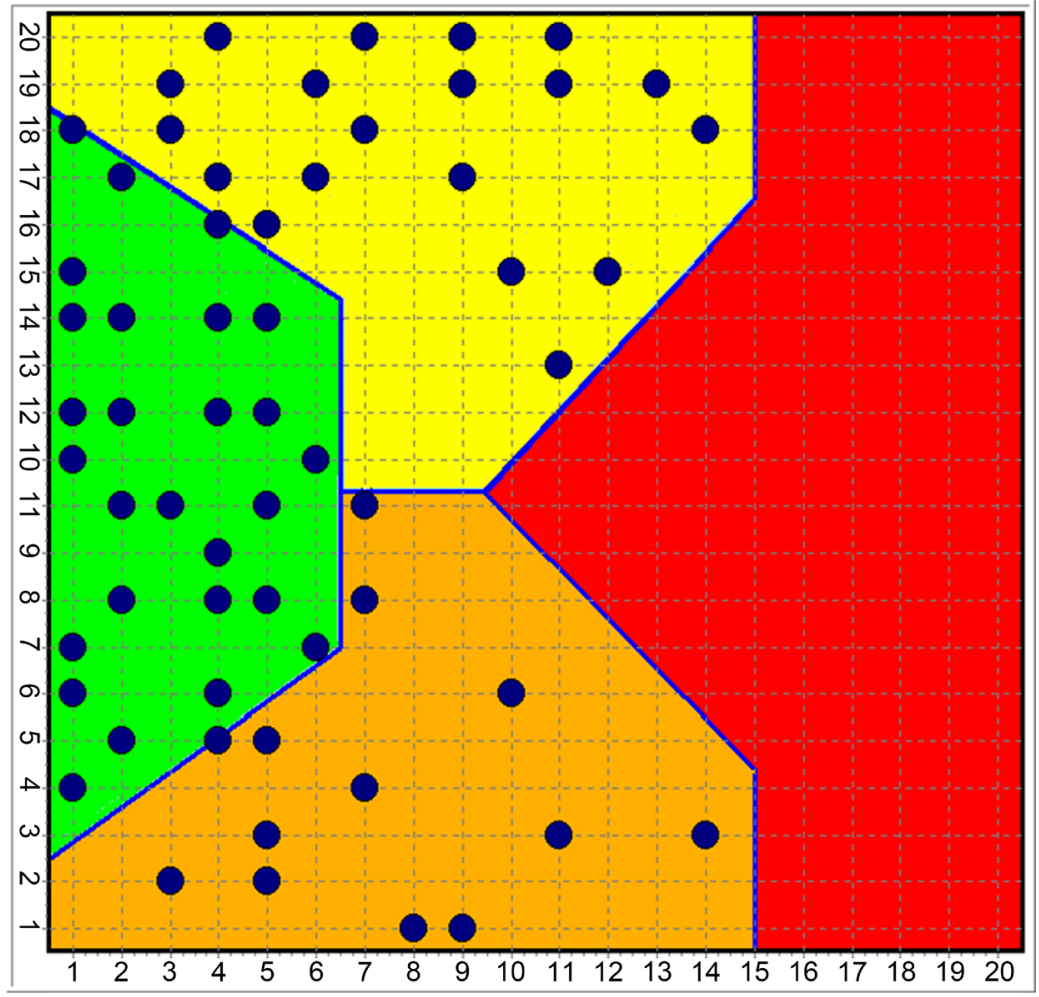

Figure 4. Distribution of normal subjects in ADAM (green = normal; red, yellow and orange $=$ pathologic $)$.

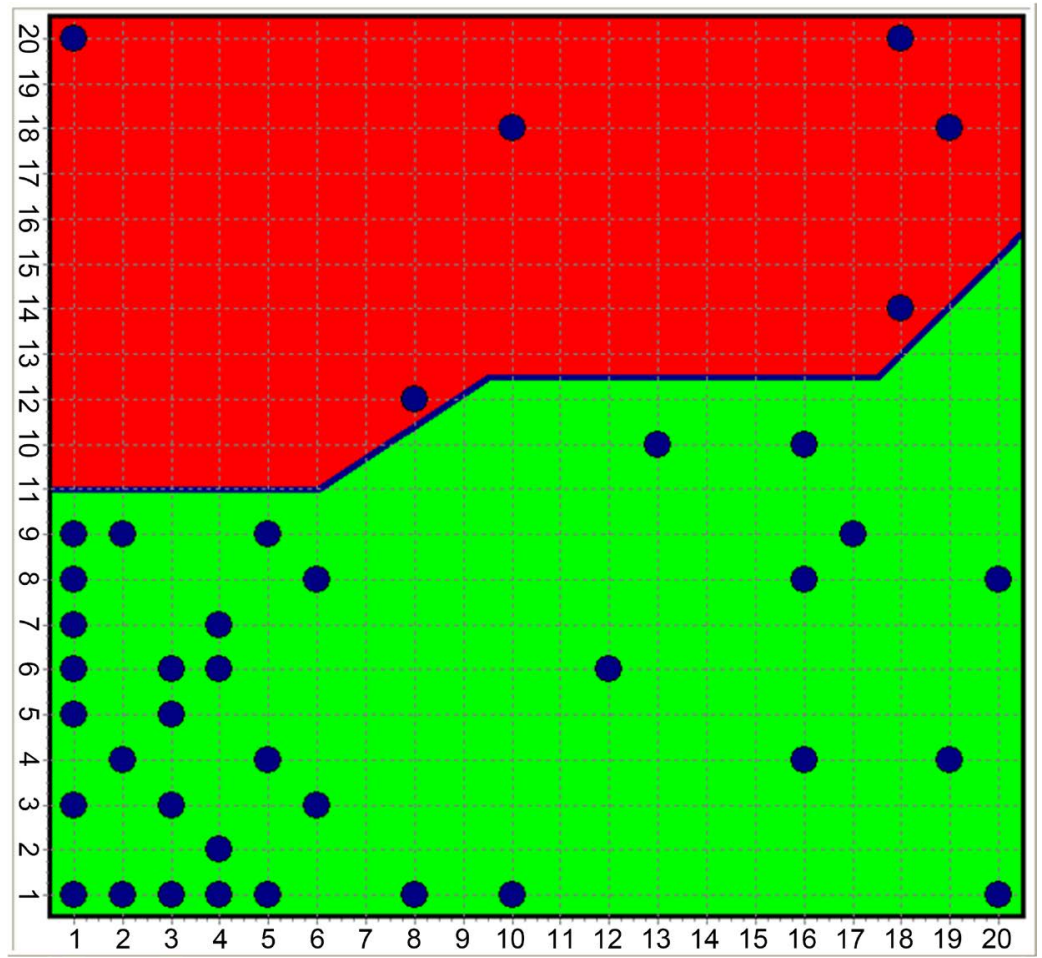

Figure 5. Distribution of the Depressive patients (first experiment) in CAIN (green $=$ normal; red $=$ pathologic $)$. 


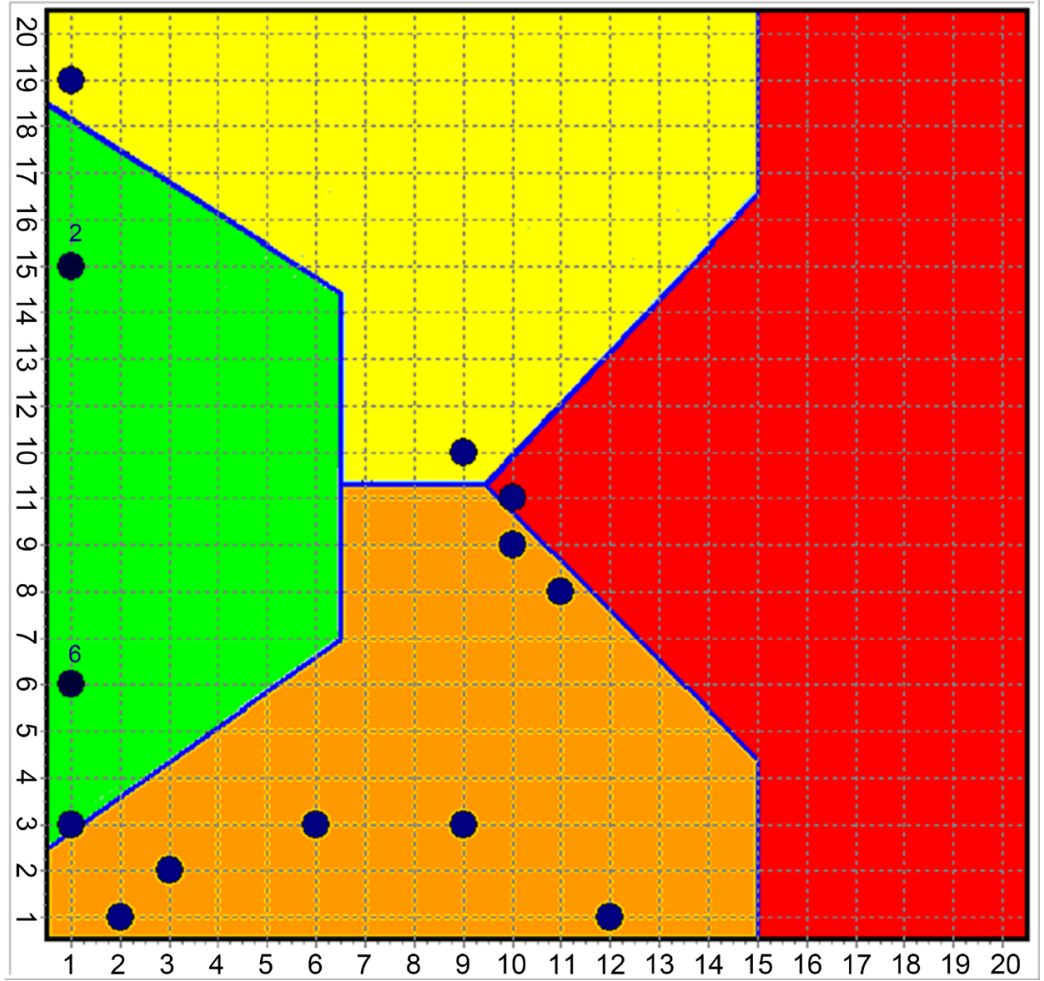

Figure 6. Distribution of the Ischemic patients (first experiment) in ADAM (green $=$ normal; red, yellow and orange $=$ pathologic $)$.

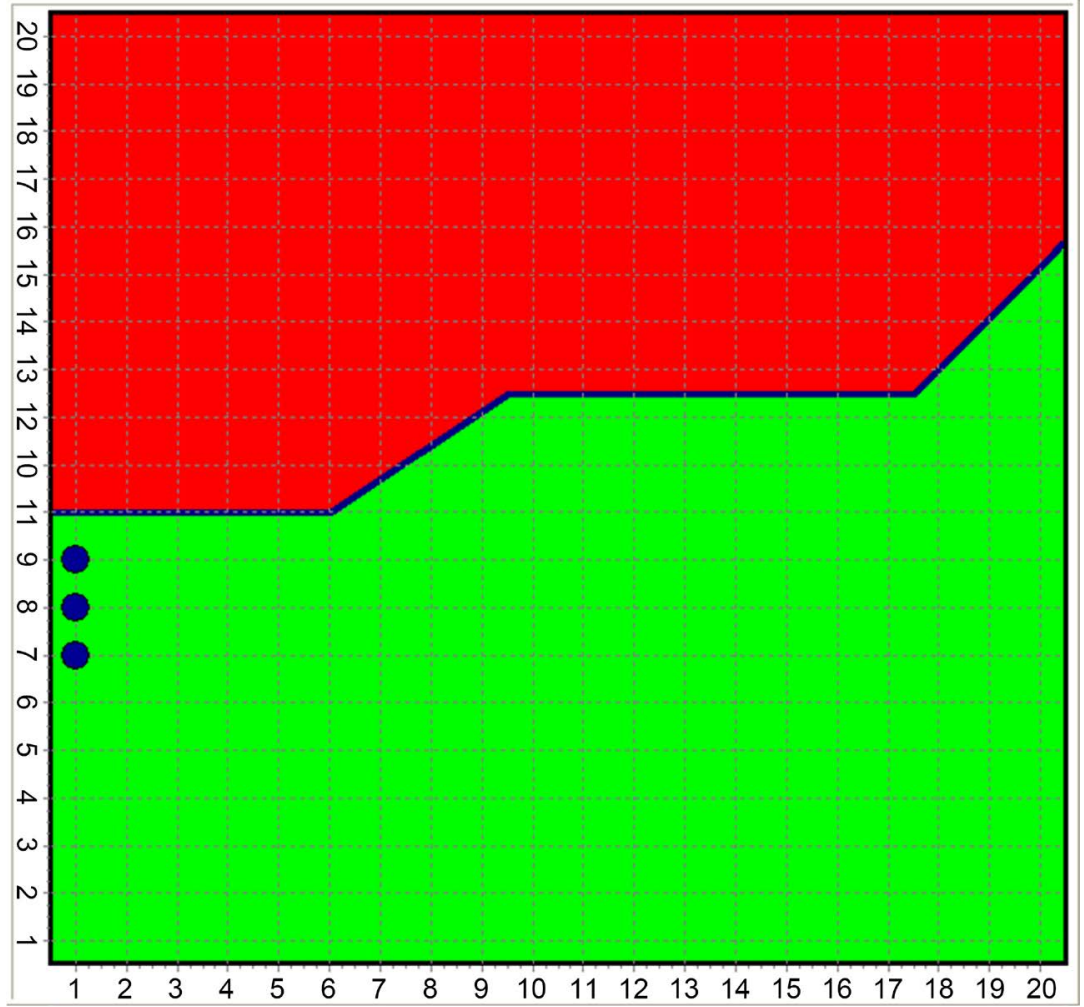

Figure 7. Patients with MD in CAIN. 


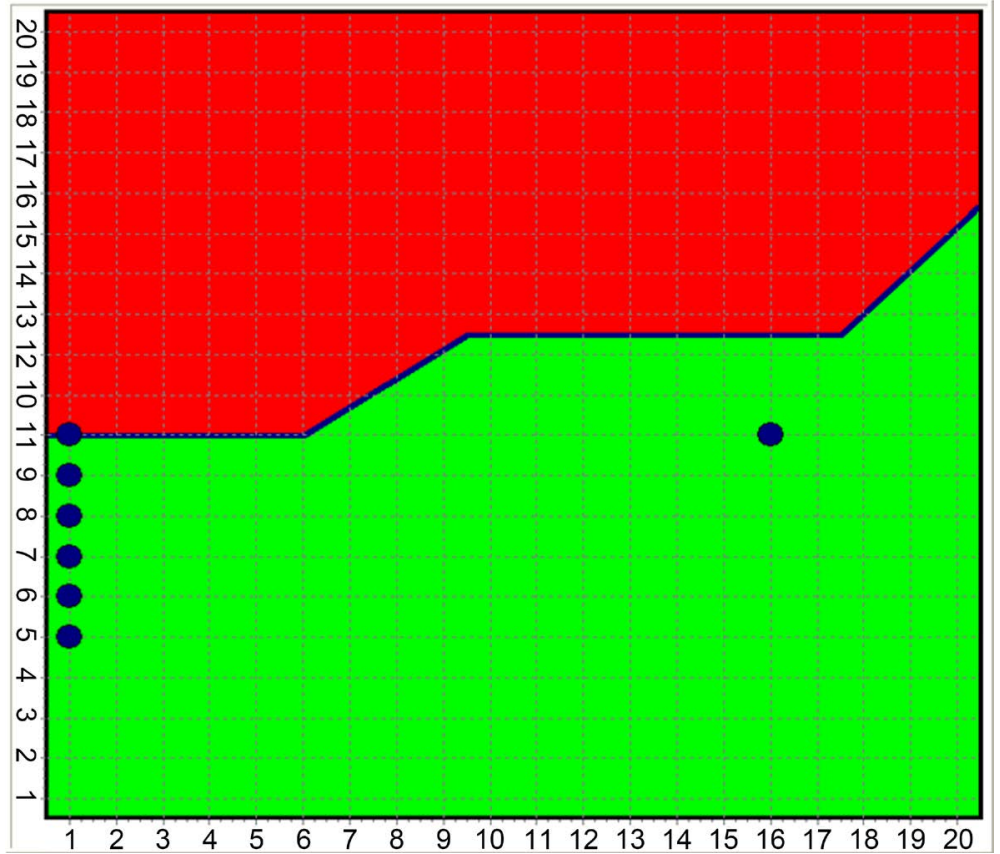

Figure 8. Patients with BD in CAIN.

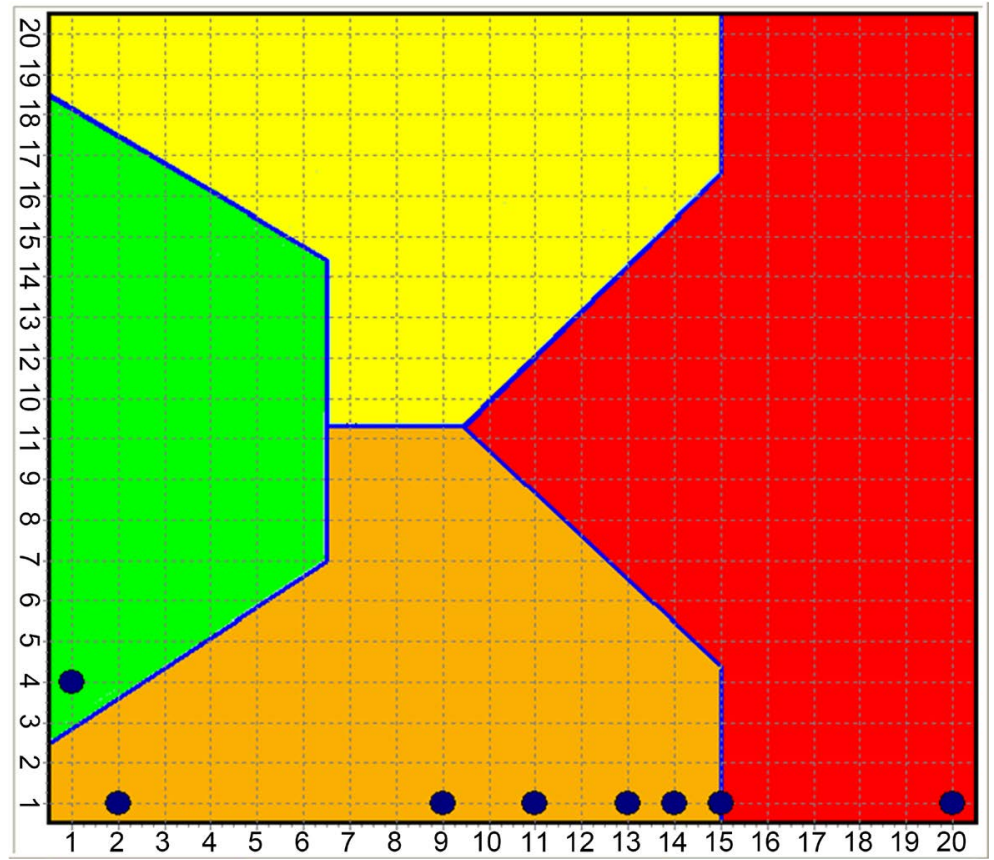

Figure 9. Subjects with severe ischemia (second trial) in ADAM.

On the contrary, the subjects with severe ischemia are mainly concentrated in the classification of the most severe bipolars with a significant impact in the position 14:1, the area in which the suicide attempts have been classified. In the assessment made by the SOM, the Ischaemic subjects in the suicide risk area, are 17 over 83 patients studied. The percentage of suicidal risk is not far from that reported in the literature as suicidal 
risk among Ischaemic (Dou et al., 2015; Larsen et al., 2010). We must remember, also, that the answer of the SOM is given on biological basis and not on subjective assessments. In the light of the results obtained, we can hypothesize that the ischemia, with its cell membrane molecular characteristic, could be responsible of the induction of a "depressive" state, a condition shared by the majority of subjects with ischemic heart disease.

\section{Conclusion}

In conclusion, it can be observed that it is very likely that cardiovascular disease can induce a "depressive" condition, probably due to the particular characteristics of the platelet membrane.

Cholesterol, Linoleic Acid and Serotonin (Cocchi \& Minuto, 2015; Cocchi et al., 2015; Tonello et al., 2015) have proved to be important factors in determining the molecular aspects of the membrane that can affect both cardiovascular and psychiatric responses to this phenomenon.

\section{References}

(2012). Tenth World Day Forth Prevention of Suicide, Rome.

Balci, B. (2011). The Modification of Serum Lipids after Acute Coronary Syndrome and Importance in Clinical Practice. Current Cardiology Reviews, 7, 272-276.

Barefoot, J. C., \& Schroll, M. (1996). Symptoms of Depression, Acute Myocardial Infarction, and Total Mortality in a Community Sample. Circulation, 93, 1976-1980. https://doi.org/10.1161/01.CIR.93.11.1976

Benedetti, S., Bucciarelli, S., Canestrari, F., Catalani, S., Mandolini, S., Marconi, V., Mastrogiacomo, A., Silvestri, R., Tagliamonte, M., Venanzini, R., Caramia, G., Gabrielli, F., Tonello, L., \& Cocchi, M. (2014). Platelet's Fatty Acids and Differential Diagnosis of Major Depression and Bipolar Disorder through the Use of an Unsupervised Competitive-Learning Network Algorithm (SOM). Open Journal of Depression, 3, 52-73. https://doi.org/10.4236/ojd.2014.32011

Boston, P. F., Dursun, S. M., \& Reveley, M. A. (1996). Cholesterol and Mental Disorder. The British Journal of Psychiatry, 169, 682-689. https://doi.org/10.1192/bjp.169.6.682

Bowden, C. L. (2001). Strategies to Reduce Misdiagnosis of Bipolar Depression. Psychiatric Services, 52, 51-55. https://doi.org/10.1176/appi.ps.52.1.51

Cay, E. L., Vetter, N., Philip, A. E., \& Dugard, P. (1972). Psychological Status during Recovery from an Acute Heart Attack. Journal of Psychosomatic Research, 16, 425-435. https://doi.org/10.1016/0022-3999(72)90068-2

Cocchi, M., \& Minuto, C. (2015). Linoleic Acid: A Milestone in Brain Evolution? From Bacteria, Fungi and Plants to Animal and Human Beings. Human Evolution, 30, 245-257.

Cocchi, M., \& Tonello, L. (2010). Bio Molecular Considerations in Major Depression and Ischemic Cardiovascular Disease. Central Nervous System Agents in Medicinal Chemistry, 10, 97-107. https://doi.org/10.2174/187152410791196378

Cocchi, M., Minuto, C., Tonello, L., \& Tuszynski, J. A. (2015). Connection between the Linoleic Acid and Psychopathology: A Symmetry-Breaking Phenomenon in the Brain? Open Journal of Depression, 4, 41-52. https://doi.org/10.4236/ojd.2015.44005

Cocchi, M., Tonello, L., \& Gabrielli, F. (2011). Platelet, Fatty Acids, Membrane Viscosity, De- 
pression and Ischemic Heart Disease: Biological-Molecular Path with Medical-Anthropology Insights. In B. Branislav (Ed.), Coronary Angiography-Advances in Noninvasive Imaging Approach for Evaluation of Coronary Artery Disease (pp. 315-352). InTech. https://doi.org/10.5772/18415

Cocchi, M., Tonello, L., \& Gabrielli, F. (2016). Cholesterol on Sunset Boulevard: The Decline of a Myth. BMJ Open, 6, e010401.

Cocchi, M., Tonello, L., \& Lercker, G. (2010). Fatty Acids, Membrane Viscosity, Serotonin and Ischemic Heart Disease. Lipids in Health and Disease, 9, 97. https://doi.org/10.1186/1476-511X-9-97

Cocchi, M., Tonello, L., Gabrielli, F., \& Pregnolato, M. (2011). Depression, Osteoporosis, Serotonin and Cell Membrane Viscosity between Biology and Philosophical Anthropology. Annals of General Psychiatry, 10, 9. https://doi.org/10.1186/1744-859X-10-9

Colquhoun, D. M., Bunker, S. J., Clarke, D. M. et al. (2013) Screening, Referral and Treatment for Depression in Patients with Coronary Heart Disease. Medical Journal of Australia, 198, 483-484. https://doi.org/10.5694/mja13.10153

De Berardis, D., Marini, S., Piersanti, M. et al. (2012). The Relationships between Cholesterol and Suicide: An Update. ISRN Psychiatry, Article ID: 387901, 6 p.

de Jonge, P., Rosmalen, J. G., Kema, I. P., Doornbos, B., van Melle, J. P., Pouwer, F. et al. (2010). Psychophysiological Biomarkers Explaining the Association between Depression and Prognosis in Coronary Artery Patients: A Critical Review of the Literature. Neuroscience \& Biobehavioral Reviews, 35, 84-90. https://doi.org/10.1016/j.neubiorev.2009.11.025

Dou, J., Tang, J., Lu, C. H., Jiang, E. S., \& Wang, P. X. (2015). A Study of Suicidal Ideation in Acute Ischemic Stroke Patients. Health and Quality of Life Outcomes, 13, 7. https://doi.org/10.1186/s12955-014-0198-9

Engelberg, H. (1992). Low Serum Cholesterol and Suicide. The Lancet, 339, 727-729. https://doi.org/10.1016/0140-6736(92)90609-7

Fava, M., Abraham, M., Pava, J., Shuster, J., \& Rosenbaum, J. (1996). Cardiovascular Risk Factors in Depression. The Role of Anxiety and Anger. Psychosomatics, 37, 31-37. https://doi.org/10.1016/S0033-3182(96)71595-5

Hare, D. L., Toukhsati, R. S., Johansson, P., \& Jaarsma, T. (2014). Depression and Cardiovascular Disease: A Clinical Review. European Heart Journal, 35, 1365-1372. https://doi.org/10.1093/eurheartj/eht462

Hedayati, S. S., Bosworth, H. B., Kuchibhatla, M., Kimmel, P. L., \& Szczech, L. A. (2006). The Predictive Value of Self-Report Scales Compared with Physician Diagnosis of Depression in Hemodialysis Patients. Kidney International, 69, 1662-1668. https://doi.org/10.1038/sj.ki.5000308

Hoffman, J. C., Mastromauro, C. A., Sowden, G. L., Wittmann, C., Rodman, R., \& Januzzi, J. L. (2011). A Collaborative Care Depression Management Program for Cardiac Inpatients: Depression Characteristics and In-Hospital Outcomes. Psychosomatics, 52, 26-33. https://doi.org/10.1016/j.psym.2010.11.021

Kaplan, J. R., Muldoon, M. F., Manuck, S. B., \& Mann, J. J. (1997). Assessing the Observed Relationship between Low Cholesterol and Violence-Related Mortality. Implications for Suicide Risk. Annals of the New York Academy of Sciences, 836, 57-80. https://doi.org/10.1111/j.1749-6632.1997.tb52355.x

Kessler, R. C., Berglund, P., Demler, O. et al. (2003). Epidemiology of Major Depressive Disorder: Results from the National Comorbidity Survey Replication (NCS-R). Journal of the American Medical Association, 289, 3095-3105. https://doi.org/10.1001/jama.289.23.3095 
Kim, J. M., Stewart, R., Kang, H. J., Jeong, B. O., Kim, S. Y., Bae, K. Y. et al. (2014). Longitudinal Associations between Serum Cholesterol Levels and Suicidal Ideation in an Older Korean Population. Journal of Affective Disorders, 152-154, 517-521. https://doi.org/10.1016/j.jad.2013.08.008

Larsen, K. K., Agerbo, E., \& Christensen, B. (2010). Myocardial Infarction and Risk of Suicide: A Population-Based Case-Control Study. Circulation, 122, 2388-2393. https://doi.org/10.1161/CIRCULATIONAHA.110.956136

Magyar-Russell, G., Thombs, B. D., Cai, J. X., Baveja, T., Kuhl, E. A., Singh, P. P. et al. (2011). The Prevalence of Anxiety and Depression in Adults with Implantable Cardioverter Defibrillators: A Systematic Review. Journal of Psychosomatic Research, 71, 223-231. https://doi.org/10.1016/j.jpsychores.2011.02.014

McCabe, P. J. (2010). Psychological Distress in Patients Diagnosed with Atrial Brillation: The State of the Science. Journal of Cardiovascular Nursing, 25, 40-51. https://doi.org/10.1097/JCN.0b013e3181b7be36

Nicholson, A., Kuper, H., \& Hemingway, H. (2006). Depression as an Aetiologic and Prognostic Factor in Coronary Heart Disease: A Meta-Analysis of 6362 Events among 146538 Participants in 54 Observational Studies. European Heart Journal, 27, 2763-2774. https://doi.org/10.1093/eurheartj/ehl338

Partonen, T., Haukka, J., Virtamo, J., Taylor, P. R., \& Lonnqvist, J. (1999). Association of Low Serum Total Cholesterol with Major Depression and Suicide. The British Journal of Psychiatry, 75, 259-262. https://doi.org/10.1192/bjp.175.3.259

Payla, Y. D., Murty, M. R., Vairamani, M., \& Chattopadhyay, A. (2008). Signaling by the Human

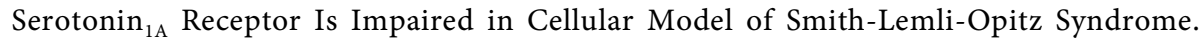
Biochimica et Biophysica Acta (BBA)-Biomembranes, 1778, 1508-1516. https://doi.org/10.1016/j.bbamem.2008.03.002

Rabe-Jablonska, J., \& Poprawska, I. (2000). Levels of Serum Total Cholesterol and LDL-Cholesterol in Patients with Major Depression in Acute Period and Remission. Medical Science Monitor, 6, 539-547.

Shrivastava, S., Pucadyil, T. J., Paila, Y. D., Ganguly, S., \& Chattopadhyay, A. (2010). Chronic Cholesterol Depletion Using Statin Impairs the Function and Dynamics of Human Serotonin ${ }_{1 \mathrm{~A}}$ Receptors. Biochemistry, 49, 5426-5435. https://doi.org/10.1021/bi100276b

Stapelberg, N. J., Neumann, D. L., Shum, D. H., McConnell, H., \& Hamilton-Craig, I. (2011). A Topographical Map of the Causal Network of Mechanisms Underlying the Relationship between Major Depressive Disorder and Coronary Heart Disease. Australian and New Zealand Journal of Psychiatry, 45, 351-369. https://doi.org/10.3109/00048674.2011.570427

Tonello, L., \& Cocchi, M. (2010). The Cell Membrane: Is It a Bridge from Psychiatry to Quantum Consciousness? NeuroQuantology, 8, 54-60. https://doi.org/10.14704/nq.2010.8.1.268

Tonello, L., Cocchi, M., Gabrielli, F., \& Tuszynski, J. A. (2015). On the Possible Quantum Role of Serotonin in Consciousness. Journal of Integrative Neuroscience, 14, 295. https://doi.org/10.1142/S021963521550017X

Tully, P. J., \& Baker, R. A. (2012). Depression, Anxiety, and Cardiac Morbidity Outcomes after Coronary Artery Bypass Surgery: A Contemporary and Practical Review. Journal of Geriatric Cardiology, 9, 197-208. https://doi.org/10.3724/SP.J.1263.2011.12221

Wynn, A. (1967). Unwarranted Emotional Distress in Men with Ischemic Heart Disease (IHD). Medical Journal of Australia, 2, 847-851. 
Submit or recommend next manuscript to SCIRP and we will provide best service for you:

Accepting pre-submission inquiries through Email, Facebook, LinkedIn, Twitter, etc. A wide selection of journals (inclusive of 9 subjects, more than 200 journals)

Providing 24-hour high-quality service

User-friendly online submission system

Fair and swift peer-review system

Efficient typesetting and proofreading procedure

Display of the result of downloads and visits, as well as the number of cited articles

Maximum dissemination of your research work

Submit your manuscript at: http://papersubmission.scirp.org/

Or contact ojd@scirp.org 